\title{
Advanced Testing and Characterization of Shear Modulus and Deformation Characteristics of Oil Sand Materials
}

\author{
Joseph K. Anochie-Boateng', and Erol Tutumluer², \\ ${ }^{1}$ Corresponding Author; JAnochieBoateng@csir.co.za; Principal Research Engineer, Built Environment Unit, \\ Council for Scientific and Industrial Research (CSIR), P O Box 395, Pretoria 0001, South Africa, Tel.: +27 12841 \\ 2947; Fax: +27 128412690 \\ ${ }^{2}$ tutumlue@illinois.edu; Professor and Paul F. Kent Endowed Faculty Scholar, Dept. of Civil and Environmental \\ Engineering, University of Illinois at Urbana-Champaign, 205 N Mathews Ave, Urbana, IL 61801, USA, Tel.: 1- \\ 217-333-8637, Fax: 1-217-333-1924
}

\begin{abstract}
Oil sands are natural deposits of sand materials that are rich in bitumen. Limited studies have been conducted to determine the dynamic behavior of oil sand materials. Recent difficulties encountered in oil sand mine fields in Canada substantiated the need to characterize the stress dependent, visco-elastic and plastic behavior of oil sand materials under dynamic loading of off-road construction and mining equipment. This paper introduces a new cyclic triaxial test procedure for determining shear modulus and deformation characteristics of oil sand materials. The test procedure was used to characterize shear moduli of three oil sand materials with varying bitumen contents. From the test results, nonlinear shear modulus models were successfully developed to characterize temperature and stress dependent behavior of the tested oil sand materials. The research findings indicate that the new laboratory approach is an improvement on conventional tests especially when oil sand materials need to be evaluated in the field for subgrade construction and equipment mobility.
\end{abstract}

KEYWORDS: oil sands, bituminous materials, shear modulus, cyclic triaxial test, bitumen, temperature. 


\section{Introduction}

Shear modulus governs shear deformation characteristics by the extent of distortion in soils and other geomaterials under applied loads. The conventional cyclic triaxial test procedure has commonly been used for measuring shear modulus in the laboratory [1]. In this standard test, the confining stress is typically held constant while the deviator stress is applied cyclically on the sample. The shear modulus is evaluated from modulus of elasticity by assuming a representative Poisson's ratio for the material tested.

The most realistic shear loading, however, occurs when cyclic confining and deviator stresses can be applied simultaneously to produce shear on the sample. Obtaining such loading conditions in the laboratory would enable close simulation of the roll and bounce and rocking motions of trucks and shovels in oil sands mine fields. The stress path of soil subjected to dynamic wheel loading in the field is shown schematically in Figure 1. The additional load imposed on the subgrade due to passing traffic results in a cycle of total stress indicated by path AT in Figure 1 and a corresponding cycle in effective stress indicated by path $\mathrm{AB}$ in Figure 1. The wheel load-induced transient stress is experienced by subgrade soils when a stress pulse due to wheel loading is transmitted from the overlying pavement layers. The pulse stress generally produces elastic behavior unless 'high deviator stress due to heavy wheel load, is involved.' The subgrade is subjected to shear loading, due to an inclined load, as the wheel approaches; increased q with no shear when the wheel is directly over the subgrade element and again shear loading (in the opposite sense to the approaching wheel) as the wheel moves away. This loading scenario is difficult to apply on soil specimens using standard cyclic load triaxial test devices in the laboratory.

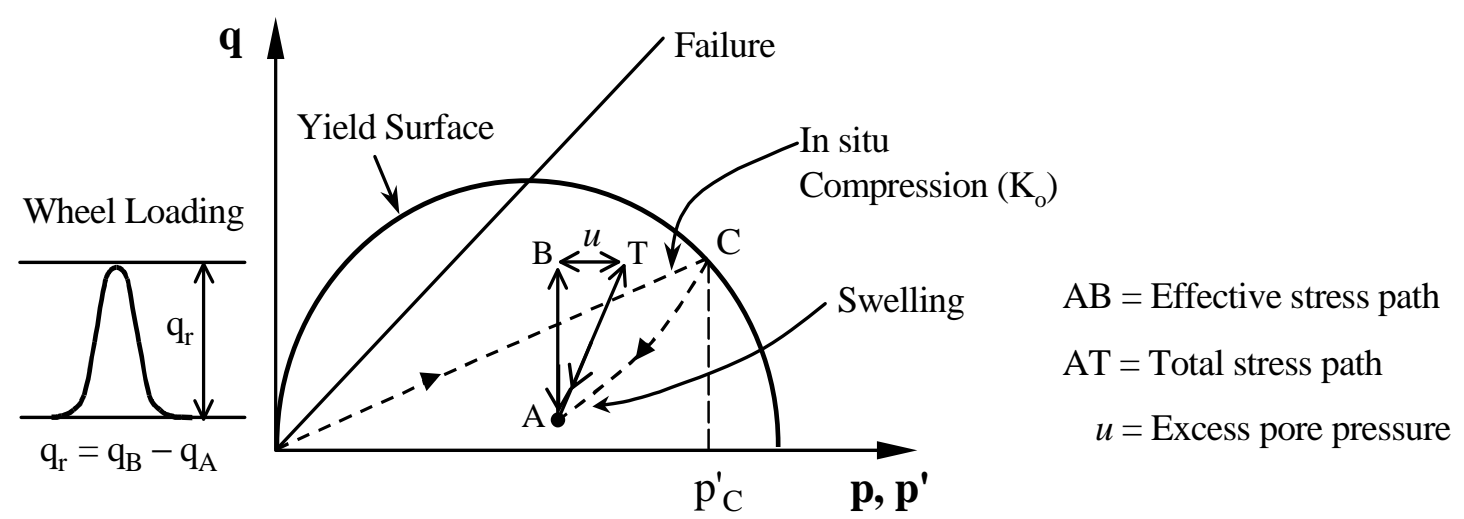

Figure 1-Effective and Total Stress Paths Due to Traffic Loading [2]. 
The loading characteristics of off-road large capacity construction and mining equipment dictate field loading stress states, and therefore, directly influence the deformation and stiffness behavior of oil sands in the field. Joseph [3] noted from field studies that a Caterpillar 797B off-road haul truck could produce vertical stresses of about $800 \mathrm{kPa}$ with confining stresses ranging between $250 \mathrm{kPa}$ and $300 \mathrm{kPa}$. He observed that the P\&H 4100 type BOSS shovels generated a static ground loading of up to $220 \mathrm{kPa}$, and could induce a ground confinement of about $70 \mathrm{kPa}$. Oil sands experienced extreme temperatures of $+40^{\circ} \mathrm{C}$ in summer and $-40^{\circ} \mathrm{C}$ in winter to make them more problematic to construction and mining equipment during summer or warmer months than in winter. Oil sand materials soften and become problematic at temperatures above $28^{\circ} \mathrm{C}$ in the field during warmer months to the extent that triaxial test could not be performed on oil sands with bitumen contents higher than 14\% [3]. To date, no comprehensive laboratory test procedure or set of data is available to determine shear modulus properties of oil sand materials although data from the traditional tests for soils such as static triaxial has been used to model oil sand materials [4-6].

The objective of this paper is to introduce a newly proposed cyclic triaxial test procedure for characterizing the shear modulus and deformation behavior of oil sand materials under realistic loading conditions. The test procedure has been followed in the laboratory on three types of oil sand materials with bitumen contents of $8.5 \%, 13.3 \%$ and $14.5 \%$ by weight. The shear modulus results obtained are compared to those from conventional cyclic triaxial tests conducted on the oil sand samples using the same applied stress states. From the test results, nonlinear shear modulus models are also developed to characterize temperature and stress dependent behavior of oil sand materials.

\section{Oil Sand Materials}

Oil sand is a generic name given to naturally occurring deposits of bituminous sand materials that are rich in bitumen content to the extent that oil can be extracted from these deposits. These materials are abundant in certain geographic zones in Canada and United States, and beyond their high demand for oil mining, oil sands can supplement the depleted mineral aggregates for road construction. The largest and most 
thoroughly studied oil sand deposits are the Alberta oil sands in Canada. The typical high content of bitumen in the oil sand composition makes these naturally occurring sands low load-bearing materials for haul trucks, shovels and other mining equipment. In situ, oil sand deposits are predominantly quartz sand surrounded by a thin film of water and fines, with bitumen filling the pore spaces between the sand grains.

A detailed review of the research findings by [3] reveals that the modulus and deformation behavior of oil sands are primarily dependent upon the applied load magnitude (wheel load in the field), rate of loading or frequency, and number of load applications. The oil sands exhibit stress-softening behavior, which is typically observed instead in fine-grained type silty and clayey soils. The composition governed by bitumen and water contents, grain size and physical properties as well as the type of applied loading (static or dynamic or both), and the nature of resulting stresses acting upon them primarily dictate the behavior.

\section{Materials Tested and Properties}

Three types of oil sand materials were selected for this study. The selection was based on their field loading behavior under construction and mining equipment and the on-going research studies. The oil sand samples were obtained from Suncor Energy, Inc. and Syncrude Canada Ltd. oil sand mines in Canada. Suncor Energy, Inc. provided two oil sand materials (SE samples) whereas Syncrude Canada Ltd. provided one oil sand material (AU sample). All the samples were shipped in separate barrels from Caterpillar, Inc. Technical Center in Peoria, Illinois to the University of Illinois Advanced Transportation Research and Engineering Laboratory (ATREL) for laboratory testing and evaluation.

The oil sand materials were initially tested for bitumen and water contents using American Association for State Highway and Transportation Officials test procedures [7,8]. The bitumen contents were found to be $8.5 \%, 13.3 \%$ and $14.5 \%$ for the SE low grade, SE high grade and AU high grade, respectively; and the water contents were $1.4 \%, 3.2 \%$ and $2.2 \%$, respectively. Accordingly, the Suncor Energy high and low grades samples were designated as SE-09 and SE-14, respectively, and the Aurora high grade was designated as AU-14. After separating bitumen from the oil sands through burning in an 
ignition oven, washed sieve analysis tests were conducted on the sand ingredients to determine particle size distributions of the three oil sands using [9]. The amount of water content in the oil sand materials is insignificantly small for suction measurement.

The gradation properties of the oil sand samples tested are listed in Table 1 and grain size distributions are plotted in Figure 2. All the three oil sand samples were uniformly graded fine to medium sands with the smallest to largest size particles ranging from $0.6 \mathrm{~mm}$ to $2.36 \mathrm{~mm}$ and the fines contents (passing No. 200 sieve or $0.075 \mathrm{~mm}$ ), ranging from $7 \%$ to $15 \%$. Similar grain size distributions for oil sand materials were reported by [10].

Table 1-Grading properties of the oil sand samples.

\begin{tabular}{ccccccc}
\hline Oil Sand ID & $\mathrm{D}_{10}$ & $\mathrm{D}_{30}$ & $\mathrm{D}_{50}$ & $\mathrm{D}_{60}$ & $\mathrm{Cu}$ & $\mathrm{Cc}$ \\
\hline SE-09 & 0.065 & 0.12 & 0.17 & 0.19 & 2.9 & 1.17 \\
SE-14 & 0.075 & 0.14 & 0.18 & 0.21 & 2.8 & 1.24 \\
AU-14 & 0.090 & 0.17 & 0.22 & 0.27 & 3.0 & 1.19 \\
\hline
\end{tabular}

$\mathrm{D}_{i}=$ grain size (in mm) corresponding to $i$-percent passing by mass.

$\mathrm{Cu}=$ coefficient of uniformity.

$\mathrm{Cc}=$ coefficient of curvature.

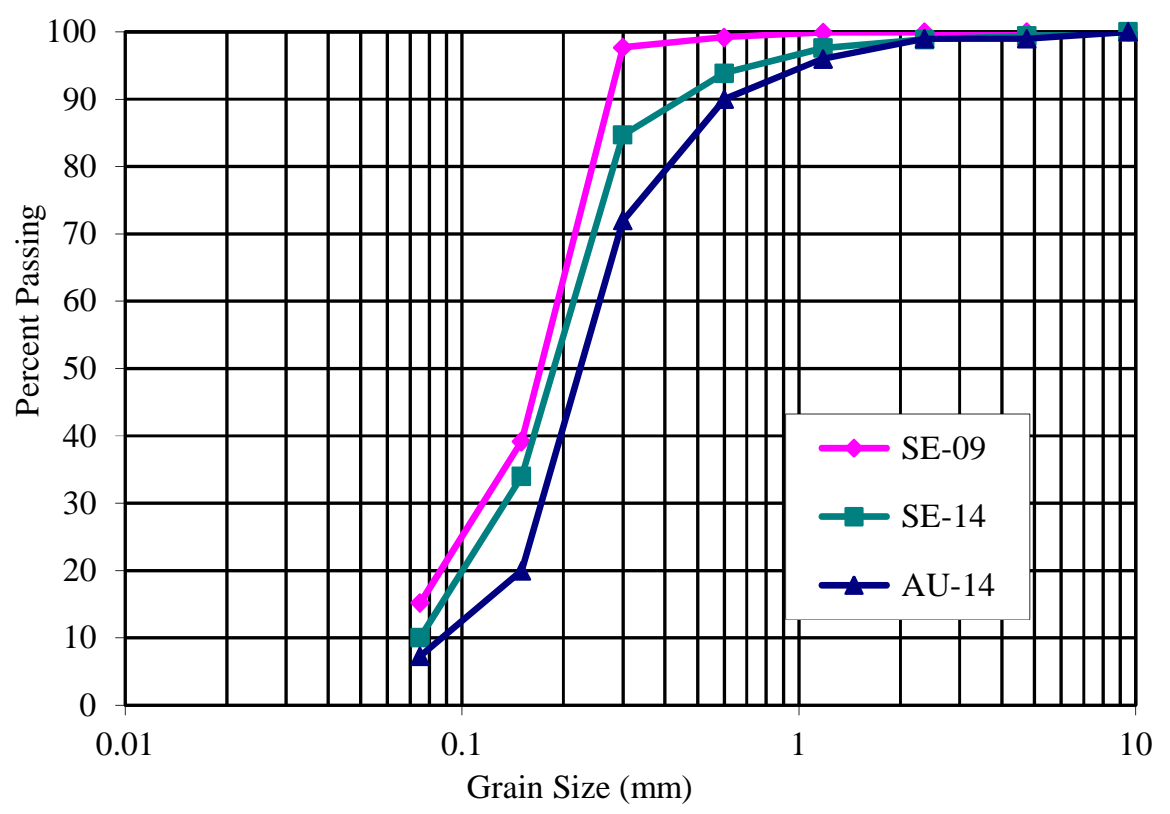

Figure 2-Particle Size Distributions of Oil the Sand Samples. 


\section{Laboratory Compaction}

Field density levels and compaction properties of the oil sands were obtained in the laboratory using a gyratory compaction device. Three duplicate specimens for each oil sand sample were produced at room temperature and tested directly in a gyratory compactor at the rate of 30 gyrations per minute, compaction pressure of $600 \mathrm{kPa}$, and gyration angle of 1.25 degrees. The number of gyrations to reach a specimen height of $150 \mathrm{~mm}$ and the actual bulk (wet) density to achieve this height were recorded for the preparation of test specimens. During compaction, changes in bulk density of the specimen were also recorded.

The variation of bulk density levels with the number of gyrations for each of the three oil sand materials is shown in Figure 3. The deformation and strength characteristics of oil sands are significantly influenced by the compaction characteristics and bitumen saturation. A considerably higher number of gyrations were needed to compact the lower bitumen content SE-09 oil sand (see Figure 3) when compared to the higher grade ones. The typical bulk densities achieved for SE-09 and SE-14 were 2,000 $\mathrm{kg} / \mathrm{m}^{3}$ at 100 gyrations and 2,050 kg/m 3 at 40 gyrations, respectively. The density achieved for AU-14 was $2,050 \mathrm{~kg} / \mathrm{m}^{3}$ at 25 gyrations. These achieved densities were very close to field values reported by [3] and computed from Eqs $1 a$ and $1 b$

Dry density $\left(\mathrm{kg} / \mathrm{m}^{3}\right)=2,150-37 \times(\%$ bitumen content $)$

Bulk density $\left(\mathrm{kg} / \mathrm{m}^{3}\right)=804+0.7 \times\left[\right.$ dry density $\left.\left(\mathrm{kg} / \mathrm{m}^{3}\right)\right]$ 


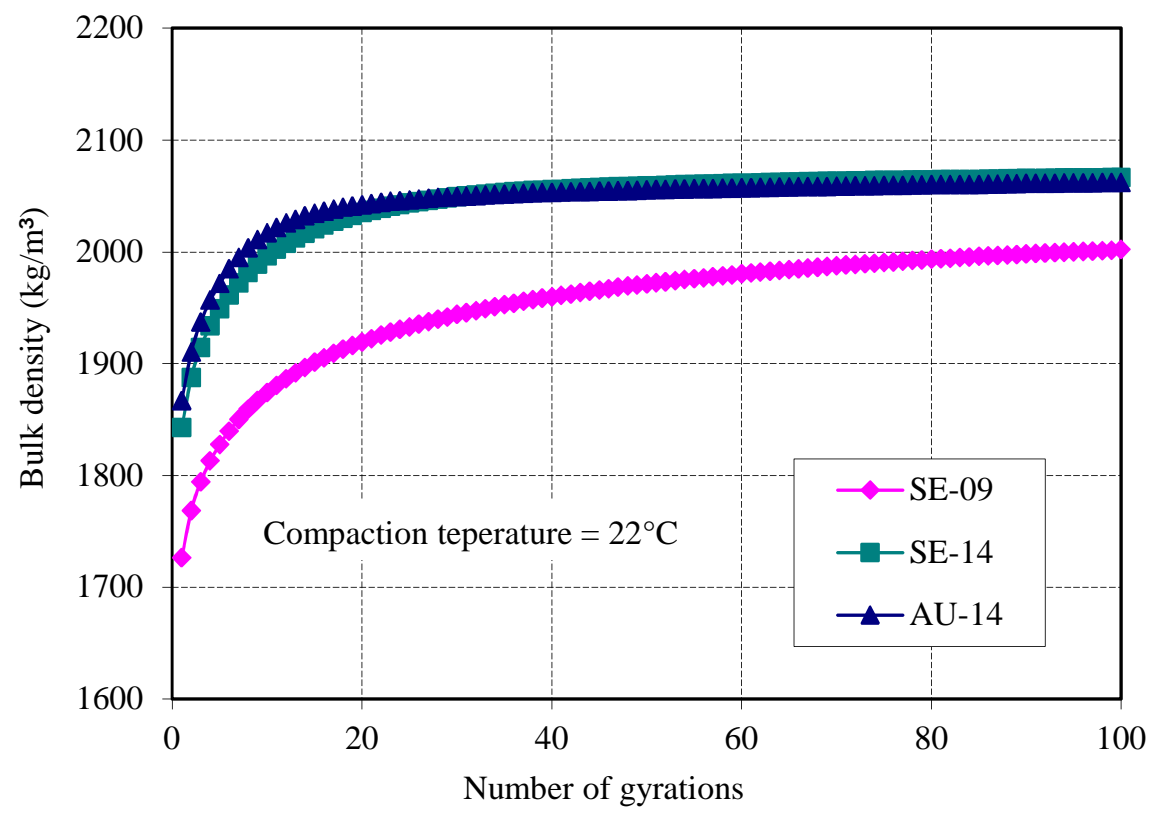

Figure 3-Gyratory Compaction Properties of Oil Sand Samples.

\section{Testing Equipment}

The shear modulus test procedures needed to utilize testing equipment and devices capable of simulating a wide range of stress conditions in the laboratory (low to high stresses, static and dynamic stresses experienced by the oil sand materials in the field). A commercially available Universal Testing Machine (UTM) with unique triaxial testing cell was deemed suitable for the developed test procedures.

The triaxial cell system offers unique capabilities in laboratory material characterization including the ability to independently cycle either confining or deviator stress in phase or out of phase, or cycle both vertical and radial stresses simultaneously at different stress levels, in compression or extension type loading to about $280 \mathrm{kPa}$ in axial direction and $140 \mathrm{kPa}$ in radial direction. An integrated control and data acquisition system provides accurate force or displacement waveform generation and control to enable automatic sequencing of test procedures. In addition, the testing system supports automated cell movement and displacement measurement with linear variable differential transducers (LVDTs) in both directions. 
A schematic diagram of the sample and the stress conditions as well as the triaxial cell system is shown in Figure 4. A pneumatic actuator applies axial stresses through a load cell, and the confining stresses are cycled through an internally built rubber membrane to the test specimen. Specimen axial and radial deformations are measured by the two externally mounted axial and radial LVDTs, respectively. This triaxial cell setup allows for the use of a one to one (1:1) specimen height to diameter ratio for testing. Seyhan [11] found close agreement between the modulus results obtained from samples at diameter to height ratios of 1:1 and 1:2 using this triaxial setup. It is worth mentioning that the proposed cyclic shear test procedure developed in this study is not limited to a particular type of testing device. The precise choice of the testing equipment and conditions depend on the capabilities of the device and flexibility of the software associated with the testing system.

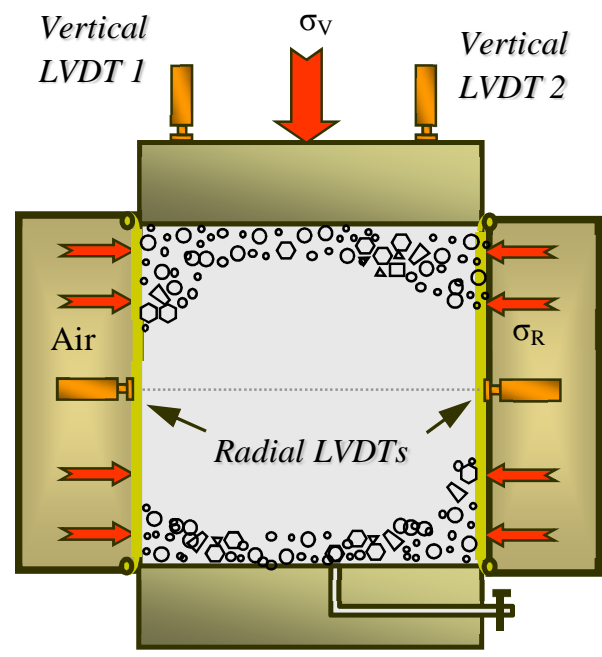

(a) Schematic of Stress Conditions on Sample

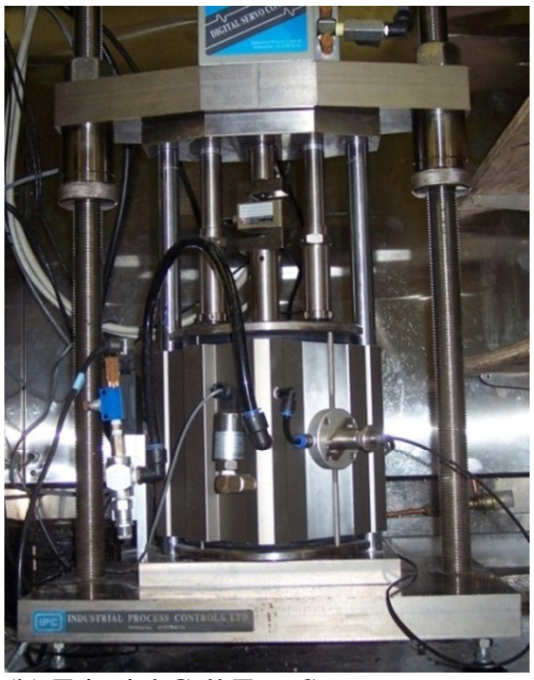

(b) Triaxial Cell Test Setup

Figure 4-Advanced Triaxial Test Setup at ATREL.

\section{Sample Preparation}

The objective was to test the oil sand materials in their natural state. The samples of loose oil sand (see Figure 5a) were re-molded as typical for a cold mix asphalt sample by gyratory compaction method to produce the triaxial specimens $150 \mathrm{~mm}$ diameter by $150 \mathrm{~mm}$ high for the shear modulus test. The samples were compacted at different density levels depending on the applied number of gyrations at the 
approximate density states in the field using the standard Superpave gyratory compactor [12] at a room temperature of approximately $21^{\circ} \mathrm{C}$.

A $150 \mathrm{~mm}$ diameter filter paper was placed at the bottom of the gyratory compaction mold. The required amount of oil sand material to achieve the expected density was then placed in the mold. Another filter paper was placed on top of the specimen and compaction was initiated until the expected specimen density was achieved by simultaneous action of static compression and shearing action resulting from the motion of specimen. When the compaction process was completed, the specimen was ejected from the mold by a pneumatic system setup. Following compaction, specimens were conditioned at the desired temperatures for a minimum of six hours in a temperature chamber prior to testing.

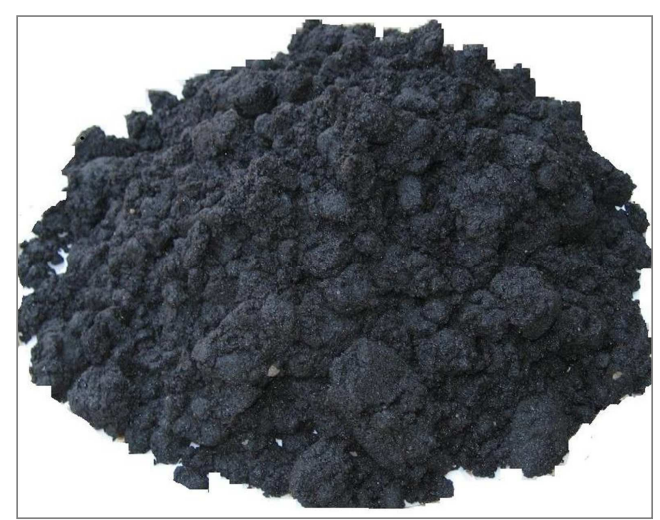

(a) Loose AU-14 Oil Sand Sample

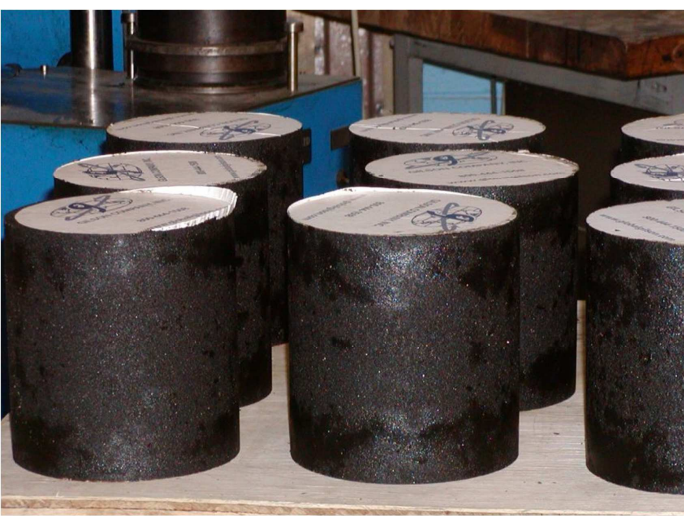

(b) Compacted AU-14 Oil Sand Sample

Figure 5-Loose and Compacted Oil Sand Samples.

\section{Experimental Design and Test Procedure}

The experimental program carried out on the three oil sand samples focused on conducting strength, deformation and modulus tests under simulated close-to-field densities and applied stress states at different load pulse durations (or loading frequencies) and temperatures. A comprehensive laboratory test program was developed in order to obtain large amount of test data for the oil sand modeling. The laboratory testing program was conducted at two temperatures, $20^{\circ} \mathrm{C}$ and $30^{\circ} \mathrm{C}$ to account for spring and hotter summer periods in the oil sand fields in Canada, respectively. The environmental chamber of the test setup controls the temperature of the specimen to an accuracy of $\pm 0.5^{\circ} \mathrm{C}$. To ensure a stable temperature, a compacted oil sand specimen (dummy) with a thermometer mounted in the center was 
placed in the chamber for temperature verification. Loading frequencies of $2 \mathrm{~Hz}$ and $10 \mathrm{~Hz}$ were considered to simulate the effects of different trafficking speeds of haul trucks and shovels as well as other mining equipment in the field. Table 2 summarizes only the test program and testing conditions followed to determine shear modulus properties of oil sands. A full factorial test matrix comprising of 12 samples and 36 tests was conducted on each oil sand material.

Table 2-Shear modulus test program and loading conditions.

\begin{tabular}{ccccc}
$\begin{array}{c}\text { Sample } \\
\text { number }\end{array}$ & $\begin{array}{c}\text { Test } \\
\text { number }\end{array}$ & $\begin{array}{c}\text { Confining } \\
\text { stress }\left(\sigma_{3}\right), \mathrm{kPa}\end{array}$ & $\begin{array}{c}\text { Cyclic } \\
\text { stress }\left(\tau_{\text {cyc }}\right), \mathrm{kPa}\end{array}$ & $\begin{array}{c}\text { Loading } \\
\text { conditions }\end{array}$ \\
\hline \multirow{2}{*}{1} & 1 & 41.4 & 20.7 & Temperature: $20^{\circ} \mathrm{C}, 30^{\circ} \mathrm{C} ;$ \\
& 2 & 41.4 & 41.4 & Frequency: $2 \mathrm{~Hz}, 10 \mathrm{~Hz}$ \\
\hline \multirow{2}{*}{2} & 3 & 69 & 20.7 & Temperature: $20^{\circ} \mathrm{C}, 30^{\circ} \mathrm{C} ;$ \\
& 4 & 69 & 41.4 & Frequency: $2 \mathrm{~Hz}, 10 \mathrm{~Hz}$ \\
& 5 & 69 & 69 & \\
\hline & 6 & 138 & 20.7 & Temperature: $20^{\circ} \mathrm{C}, 30^{\circ} \mathrm{C} ;$ \\
& 7 & 138 & 41.4 & Frequency: $2 \mathrm{~Hz}, 10 \mathrm{~Hz}$ \\
& 8 & 138 & 69 & \\
\end{tabular}

The proposed cyclic triaxial test procedure proposed for the oil sand materials applies static and dynamic loads in both axial and radial directions to evaluate shear modulus behavior. The proposed test procedure applies cyclic stresses which are $90^{\circ}$ out of phase from the applied deviatoric stress changes as indicated in Figure $6\left(\sigma_{\mathrm{d}}\right.$ is the deviatoric stress; $\left.\sigma_{\mathrm{d}} / 2=\tau_{\mathrm{cyc}}\right)$. The applied stress path is in the vertical direction similar to that of shear loading that would be induced in the field by large capacity off-road construction and mining equipment on the oil sand materials. For the application of the shear stresses, two alternating pulses of the same magnitude are applied at the same time in the vertical and radial directions on the samples.

At different stress levels strains are recorded in vertical and radial directions. The shear modulus $(G)$ is calculated using the shear strain and the applied shear stress (Eq 2).

$$
\tau=\sigma_{1}-\sigma_{3} ; \quad \gamma=\frac{2}{3} \times\left(\varepsilon_{1}-\varepsilon_{3}\right) ; \quad G=\frac{\tau}{\gamma}
$$

where: 
$\tau=$ applied shear stress,

$\sigma_{1}, \sigma_{3}=$ axial and radial (confining) stresses, respectively, and

$\gamma=$ shear strain; $\varepsilon_{1}$ and $\varepsilon_{3}$ are axial and radial strains, respectively.
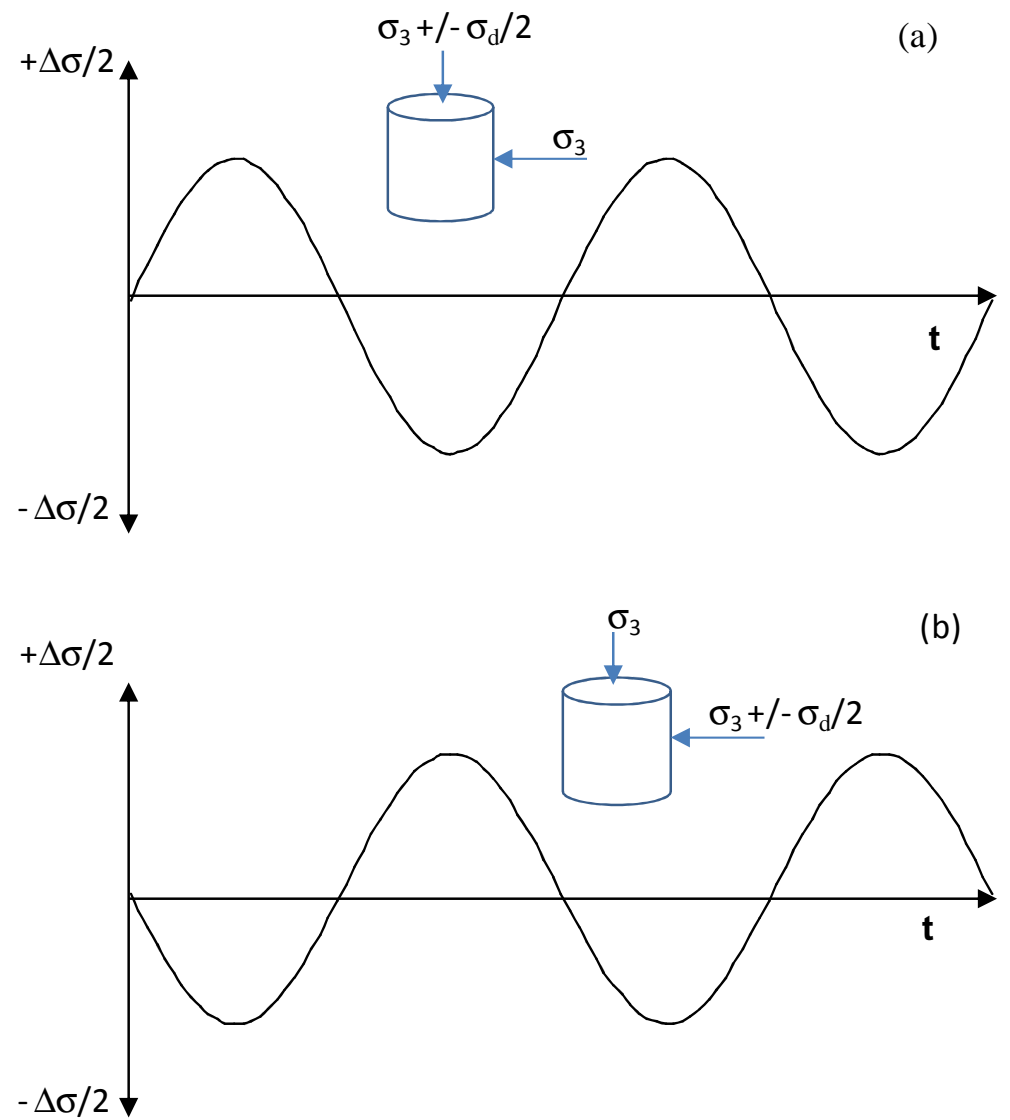

Figure 6-Schematic of Stress Conditions Applied on the Oil Sand Samples.

\section{Laboratory Testing of Oil Sand Samples}

Shear modulus tests were performed on the three oil sand samples (i.e., SE-09, SE-14, and AU-14), using the proposed cyclic triaxial shear test procedure. The testing involved applying varying frequencies of continuous sinusoidal load to the test specimen, and measuring shear stress and shear strain responses to directly obtain shear modulus properties. During testing, the gyratory compacted oil sand specimens were subjected to different applied stress states and loading conditions as listed in Table 2. For each confining stress, a minimum cyclic shear stress of $20.7 \mathrm{kPa}$ was applied on the test samples, and increased until the 
shear stress reached a value equal to the maximum confining stress of $138 \mathrm{kPa}$. Each cyclic stress and constant confining stress $\sigma_{3}$ pair was applied on one specimen with the cyclic stress pulsed in the both axial and radial directions, simultaneously, for a total of 25 cycles. Each stress state applied was recorded, and the resulting average recoverable axial and radial strain responses and the applied cyclic stress of the last five cycles were used to compute the shear modulus of the oil sand materials (Eq 1). A full factorial test matrix comprising 108 tests was conducted on the three oil sand samples at the two test temperatures and loading frequencies.

In addition, conventional type cyclic tests were also performed on the oil sand materials using the ASTM standard test procedure [1] to compare test results to the newly proposed cyclic triaxial shear modulus tests for the oil sand samples at the test temperature of $20^{\circ} \mathrm{C}$ and the loading frequency of $2 \mathrm{~Hz}$. It should be mentioned that in the conventional triaxial compression test, a constant all-around confinement is applied on the specimen with only the deviator stress cycled. The temperature of $20^{\circ} \mathrm{C}$ selected for the comparison is close to the room temperature of $21^{\circ} \mathrm{C}$ at which the oil sand samples were compacted, and the lower loading frequency of $2 \mathrm{~Hz}$ was selected for ease in testing. Gyratory compacted specimens were subjected to the same stress states and loading conditions as the proposed cyclic triaxial shear modulus tests (see Table 2). Overall, 27 standard cyclic tests were conducted on the three oil sand samples.

\section{Analyses and Discussion of Test Results}

\section{Effect of Loading Conditions on Oil Sands}

The shear modulus test data obtained for all the three oil sand materials were analyzed. The applied shear stress $(\tau)$ and corresponding shear strain $(\gamma)$, as well as the shear modulus $(G)$ of the samples were computed from Eq 1. The test results for SE-09, SE-14 and AU-14 oil sand samples at $20^{\circ} \mathrm{C}$ and at $30^{\circ} \mathrm{C}$, are summarize in Table 3 and Table 4, respectively. Each table provides the shear modulus values at frequencies of $2 \mathrm{~Hz}$ and $10 \mathrm{~Hz}$. It can be seen that the shear moduli of SE-09 samples are generally higher than those of SE-14 and AU-14 samples. No significant differences were found between shear moduli of the AU-14 (bitumen content $w_{\mathrm{b}}=14.5 \%$ ) and SE-14 (bitumen content $w_{\mathrm{b}}=13.3 \%$ ) samples, which could 
be attributed to the similar amount of bitumen contents in the two samples. Thus, the amount of bitumen content appears to affect the shear modulus properties of oil sand materials. These laboratory findings also agree very well with the observed field stiffness behavior of oil sand materials [3]. On the average, shear moduli of SE-09 sample were about 1.97 times of the average shear moduli of the AU-14 sample.

As expected of bituminous materials, the shear modulus is generally lower at $30^{\circ} \mathrm{C}$ than at $20^{\circ} \mathrm{C}$ for all the oil sand samples. Also, shear moduli were found to be lower at $2 \mathrm{~Hz}$ than at $10 \mathrm{~Hz}$ for all the oil sand samples. The average shear modulus at $20^{\circ} \mathrm{C}$ was about 1.5 to 2 times of the shear modulus at $30^{\circ} \mathrm{C}$ for the oil sand samples tested. On the other hand, the average shear modulus at $10 \mathrm{~Hz}$ was about 2 to 3 times of the shear modulus at $2 \mathrm{~Hz}$ for all the oil sand samples tested at the two test temperatures.

Table 3-Stress states and results of proposed shear loading test at $20^{\circ} \mathrm{C}$.

\begin{tabular}{|c|c|c|c|c|c|c|c|}
\hline \multicolumn{2}{|c|}{ Stress state $(\mathrm{kPa})$} & \multicolumn{3}{|c|}{ Shear modulus at $2 \mathrm{~Hz}(\mathrm{MPa})$} & \multicolumn{3}{|c|}{ Shear modulus at $10 \mathrm{~Hz}(\mathrm{MPa})$} \\
\hline$\sigma_{3}$ & $\tau_{\mathrm{cyc}}$ & SE-09 & SE-14 & AU-14 & SE-09 & SE-14 & AU-14 \\
\hline 41.4 & 20.7 & 41.6 & 15.8 & 15.9 & 86.2 & 51.2 & 37.3 \\
\hline 41.4 & 41.4 & 20.7 & 10.5 & 8.4 & 63.3 & 47.7 & 35.6 \\
\hline 69 & 20.7 & 94.4 & 53.2 & 40.5 & 158.1 & 116.4 & 89.3 \\
\hline 69 & 41.4 & 34.2 & 23.7 & 20.3 & 99.1 & 74.0 & 60.6 \\
\hline 69 & 69 & 22.9 & 17.8 & 16.2 & 77.4 & 68.9 & 54.2 \\
\hline 138 & 20.7 & 232.5 & 158.8 & 128.7 & 298.0 & 222.5 & 214.5 \\
\hline 138 & 41.4 & 131.7 & 66.1 & 61.4 & 212.5 & 133.2 & 121.5 \\
\hline 138 & 69 & 62.7 & 38.9 & 36.6 & 170.9 & 119.1 & 108.0 \\
\hline 138 & 138 & 39.7 & 30.6 & 24.9 & 104.8 & 95.5 & 91.8 \\
\hline
\end{tabular}

Table 4-Stress states and results of proposed shear loading test at $30^{\circ} \mathrm{C}$.

\begin{tabular}{|c|c|c|c|c|c|c|c|}
\hline \multicolumn{2}{|c|}{ Stress state $(\mathrm{kPa})$} & \multicolumn{3}{|c|}{ Shear modulus at $2 \mathrm{~Hz}(\mathrm{MPa})$} & \multicolumn{3}{|c|}{ Shear modulus at $10 \mathrm{~Hz}(\mathrm{MPa})$} \\
\hline$\sigma_{3}$ & $\tau_{\mathrm{cyc}}$ & SE-09 & SE-14 & AU-14 & SE-09 & SE-14 & AU-14 \\
\hline 41.4 & 20.7 & 23.4 & 14.5 & 7.3 & 50.7 & 38.0 & 16.7 \\
\hline 41.4 & 41.4 & 11.0 & 10.0 & 6.8 & 28.2 & 27.8 & 15.6 \\
\hline 69 & 20.7 & 72.7 & 39.5 & 23.1 & 102.2 & 74.7 & 54.0 \\
\hline 69 & 41.4 & 21.6 & 15.4 & 11.7 & 52.2 & 43.1 & 31.3 \\
\hline 69 & 69 & 15.8 & 13.0 & 9.9 & 31.5 & 34.3 & 24.5 \\
\hline 138 & 20.7 & 219.6 & 129.5 & 124.6 & 272.4 & 194.6 & 163.1 \\
\hline 138 & 41.4 & 116.4 & 56.9 & 34.9 & 167.5 & 112.8 & 74.4 \\
\hline 138 & 69 & 41.8 & 28.0 & 24.6 & 111.0 & 80.3 & 49.1 \\
\hline 138 & 138 & 25.7 & 22.1 & 19.3 & 48.6 & 49.9 & 32.3 \\
\hline
\end{tabular}


Thus, the effect of reducing loading frequency is similar to the effect of increasing the test temperature. This behavior is typically observed for bituminous materials, in which stiffness increases at low temperatures and decreases at low frequencies. As listed in Table 3 and Table 4, the shear moduli decrease with increasing applied cyclic stresses. In addition, the test results show that the shear modulus increases with increasing applied confining pressures for the three oil sand materials, i.e., SE-09, SE-14 and AU-14 samples. This observation also supports the stress-softening behavior reported for oil sand materials in the field [13]. The effect of the applied cyclic stress is also observed from the test results.

Direct shear tests conducted on the three oil sand samples [14] indicated that the SE-09 sample possesses an average friction angle of $36.2^{\circ}$ and cohesion intercept of $11.9 \mathrm{kPa}$, for the two test temperatures, $20^{\circ} \mathrm{C}$ and $30^{\circ} \mathrm{C}$, whereas the SE-14 sample possesses a friction angle of $33.2^{\circ}$ and a cohesion intercept of $22.4 \mathrm{kPa}$. The average strength results for the $\mathrm{AU}-14$ sample at $20^{\circ} \mathrm{C}$ and $30^{\circ} \mathrm{C}$ found the friction angle to be $30.6^{\circ}$ with a cohesion intercept of $27.1 \mathrm{kPa}$, comparable to that of the SE-14 sample, especially the cohesion parameter. Accordingly, the SE-09 sample is expected to be stiffer and exhibit greater potential to resist shear deformation in the oil sand mining pits than the SE-14 and AU-14 samples.

These factors of temperature, bitumen content and applied stress states have not been studied in a comprehensive way to model the shear behavior of oil sands for road construction. It should be noted that the rheological properties of bitumen in the oil sands were not considered in detail. This is partly due to the fact that no information was found from the recent field study conducted on these oil sand materials in relation to the rheological properties of the bitumen [3]. The effect of bitumen on the dynamic shear modulus of compacted oil sands is governed by the viscous properties of the reconstituted materials as demonstrated in Figure 7. This is analogous to the effect of asphalt binder on asphalt concrete. The figure shows typical trends observed in the test data for SE-09, SE-14 and AU-14, respectively at the loading frequency of $2 \mathrm{~Hz}$, test temperature of $30^{\circ} \mathrm{C}$ and the last five load cycles. These trends suggest that the compacted oil sands materials exhibit viscous behavior. The effect of non-Newtonian bitumen was 
ignored in the analysis because all three oil sand samples were obtained from the same natural oil sand deposit. Thus, it can be reasonably assumed that the rheological properties should be similar.
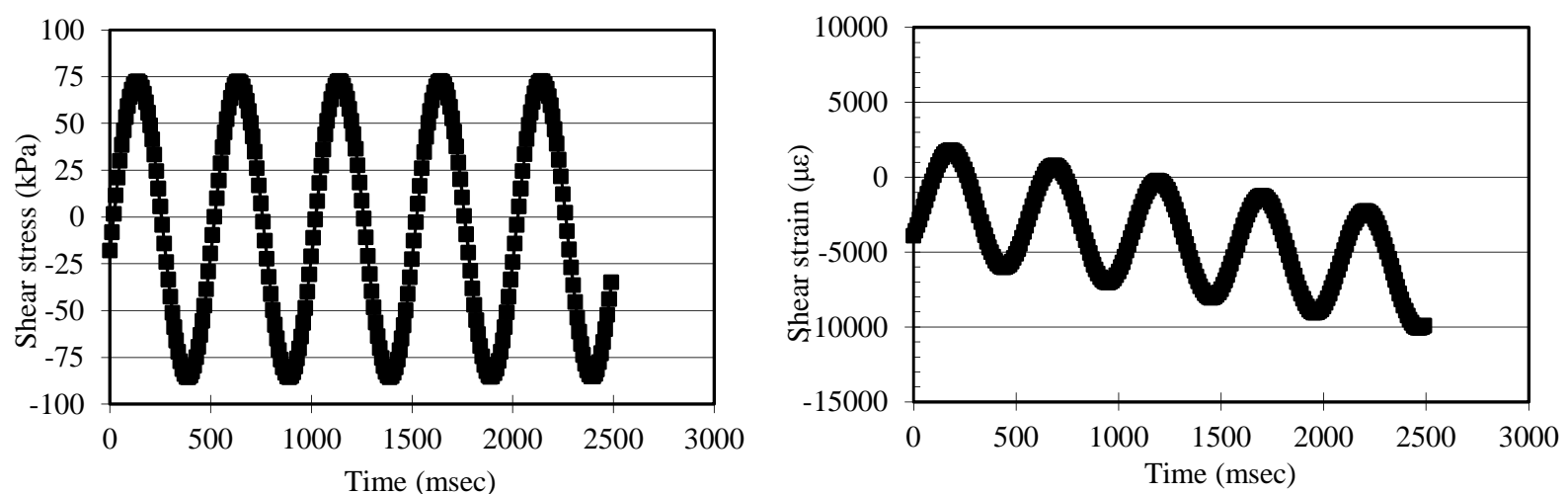

(a) SE-09 Sample
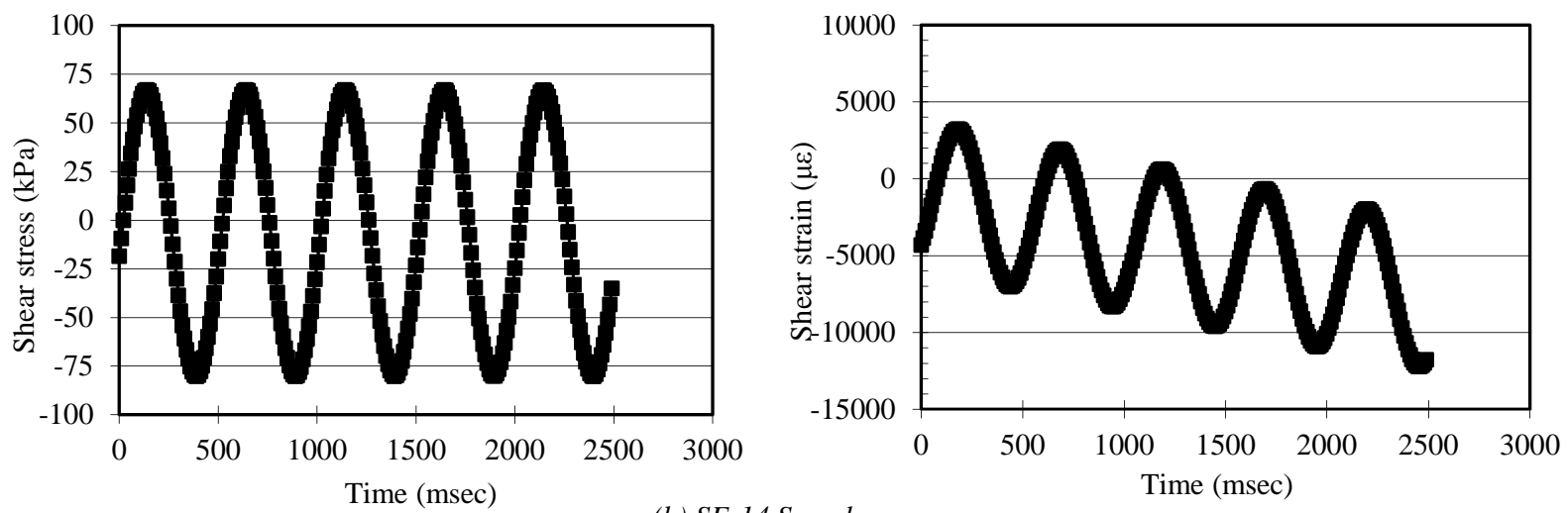

(b) SE-14 Sample
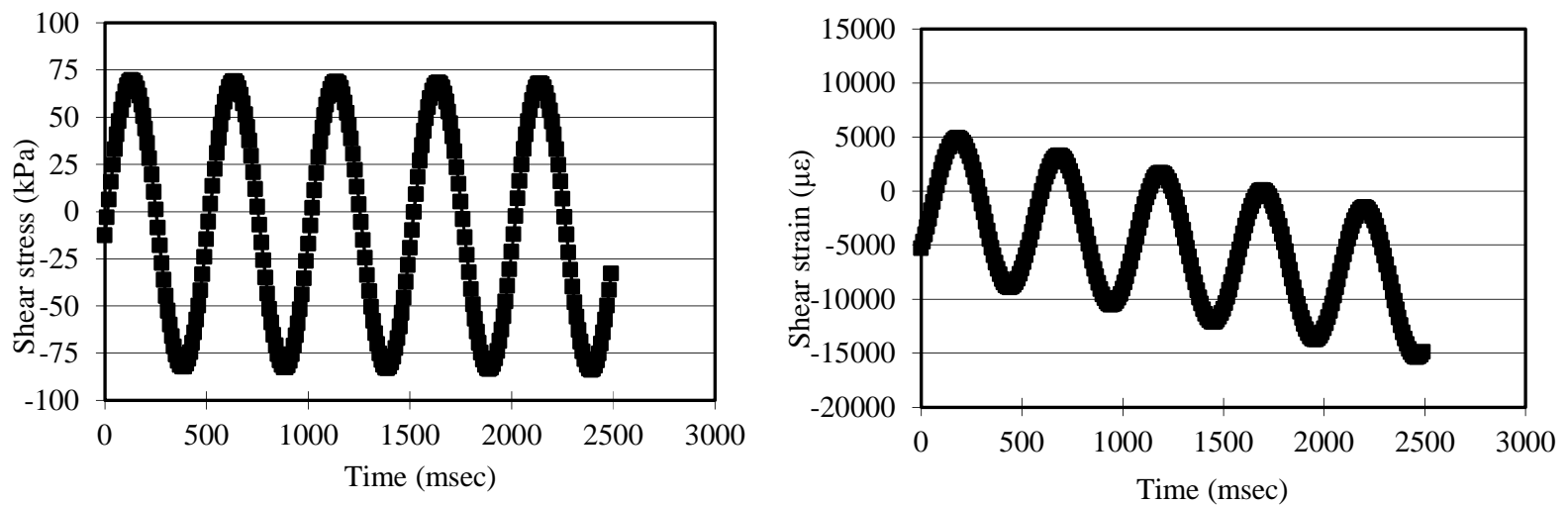

(c) AU-14 Sample

Figure 7-Axial Shear Stress and Strain vs. Time at $2 \mathrm{~Hz}, 30^{\circ} \mathrm{C}$ for Oil Sand Samples. 


\section{Correlation between shear moduli values}

Shear moduli obtained from conventional cyclic triaxial tests compared with those subjected to the new cyclic triaxial shear loading tests are shown in Table 5. The average shear modulus measured from the conventional test was about two times higher than the average value obtained from the proposed shear modulus test considering the data from all the three oil sand samples. It is noted that the major difference between the conventional triaxial and proposed cyclic triaxial shear modulus test procedures is such that in the newly proposed test, the confining stress is cycled in phase with the axial shear stress and the axial specimen deformations are generally larger due to the lack of a constant all-around confinement on the specimen. This phenomenon resulted in lower shear moduli compared to the values measured from the conventional cyclic loading tests. The difference could also be attributed to the fact that most soils display different deformation modulus along different loading stress paths. However, shear moduli from the proposed cyclic triaxial shear tests would better simulate critical field loading conditions of haul trucks and shovels, which at any time impose varying magnitudes of axial, radial and shear stresses in the oil sand materials during mining activities. Also, it would be more conservative to characterize these materials by the proposed cyclic shear loading since oil sands experience in the field induced dynamic loading in all directions.

Table 5-Comparison of shear moduli obtained from the new and conventional triaxial shear tests.

\begin{tabular}{|c|c|c|c|c|c|c|c|}
\hline \multicolumn{2}{|c|}{ Stress state $(\mathrm{kPa})$} & \multicolumn{3}{|c|}{ Gps (MPa) } & \multicolumn{3}{|c|}{ G (MPa) } \\
\hline$\sigma_{3}$ & $\tau_{\mathrm{cyc}}$ & SE-09 & SE-14 & AU-14 & SE-09 & SE-14 & AU-14 \\
\hline 41.4 & 20.7 & 41.6 & 15.8 & 15.9 & 89.0 & 72.9 & 41.5 \\
\hline 41.4 & 41.4 & 20.7 & 10.5 & 8.4 & 39.1 & 34.3 & 20.3 \\
\hline 69 & 20.7 & 94.4 & 53.2 & 40.5 & 155.3 & 122.5 & 76.3 \\
\hline 69 & 41.4 & 34.2 & 23.7 & 20.3 & 84.6 & 69.1 & 36.4 \\
\hline 69 & 69 & 22.9 & 17.8 & 16.2 & 36.2 & 34.3 & 21.0 \\
\hline 138 & 20.7 & 232.5 & 158.8 & 128.7 & 314.0 & 259.5 & 195.8 \\
\hline 138 & 41.4 & 131.7 & 66.1 & 61.4 & 234.9 & 187.8 & 131.1 \\
\hline 138 & 69 & 62.7 & 38.9 & 36.6 & 149.6 & 117.7 & 66.5 \\
\hline 138 & 138 & 39.7 & 30.6 & 24.9 & 40.5 & 37.6 & 25.1 \\
\hline
\end{tabular}

Gps: $\quad$ Shear modulus obtained from the proposed shear triaxial test.

G: $\quad$ Shear modulus obtained from conventional triaxial test. 
The correlation between the shear modulus properties obtained from the new cyclic triaxial shear and conventional cyclic triaxial tests for the combined test data of the three oil sand samples are shown in Figure 8. Regression curve fit and 45-degree line (line of equality) were drawn in the data points to display the correlations between the shear modulus values obtained from the two test procedures. There is a fairly good correlation $\left(\mathrm{R}^{2}\right.$ value $\left.=0.88\right)$ between shear modulus obtained from the cyclic triaxial shear and the conventional cyclic tests.

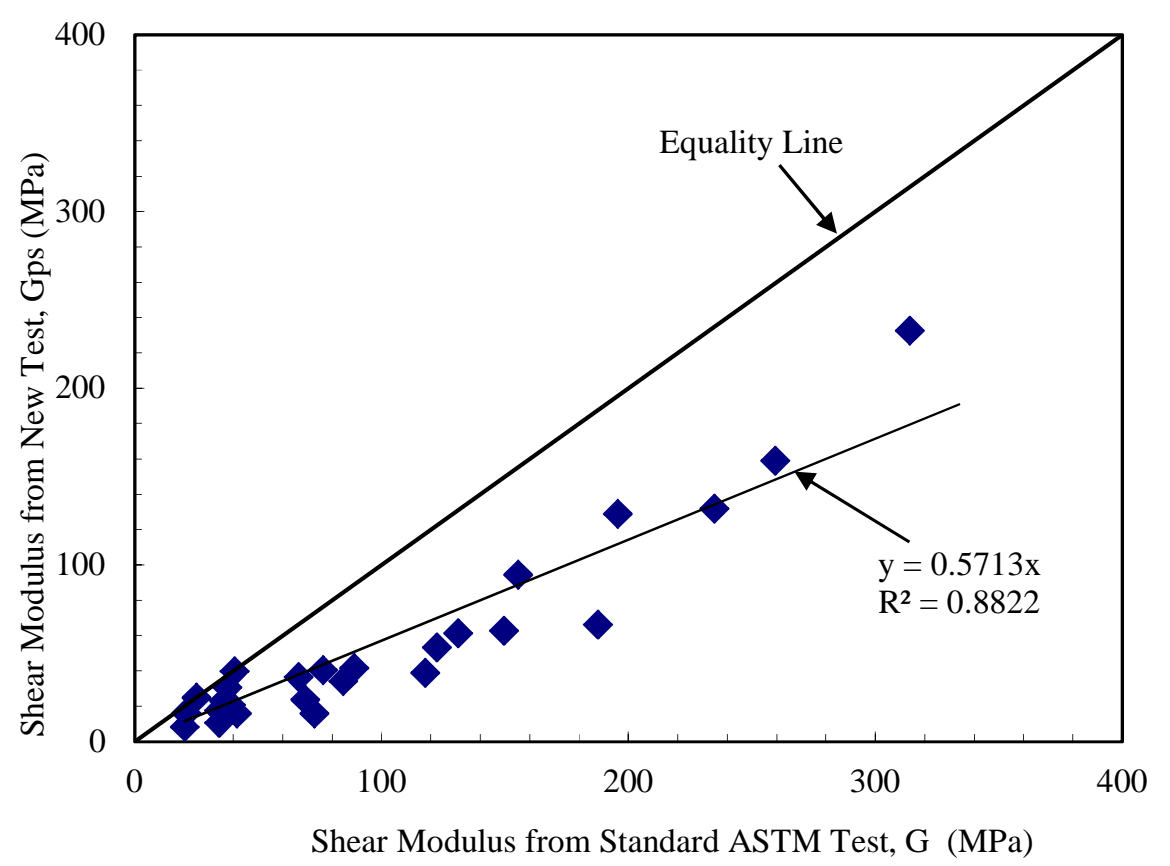

Figure 8-Relationship between Gps and G for all Oil Sand Materials Tested.

\section{Oil Sand Shear Modulus Reduction Curves}

Shear modulus reduction curves are commonly used to model the relationship between a shear modulus at a certain mobilized shear strain and the maximum shear modulus at the small strain level (often $<0.001 \%$ ). The maximum shear modulus $\mathrm{G}_{\max }$ and the shear modulus ratio $\mathrm{G} / \mathrm{G}_{\max }$ or normalized shear modulus have generally been used to characterize the shear deformation characteristics at different strain levels [15-17]. At the small strain level below $0.001 \%$, it is assumed that the soil shear modulus becomes a constant $G_{\max }$, and the ratio $\mathrm{G} / \mathrm{G}_{\max }$ is then equal to one. 
The modulus reduction concept was applied to the data generated for the oil sand samples. The normalized shear modulus $\mathrm{G} / \mathrm{G}^{\prime}$ ( $\mathrm{G}^{\prime}$ is the maximum shear modulus value within the test data) against the shear strain $\gamma$ for the oil sand samples at different loading frequencies and temperatures is shown in Figure 9. It can be seen that data points for all the three oil sand samples fall within the specific range of a general trend, and there is little effect of temperature and loading frequency on the $G / G^{\prime}-\gamma$ relations at low shear strains. Note that the modulus reduction results presented for the oil sand materials are based on high strain levels $(>0.001 \%)$. This is expected since high strain levels are experienced by the oil sand materials under haul trucks and shovels in the field.

Assuming that the minimum shear strain is a good approximation for obtaining the maximum shear modulus from the test data, the maximum shear modulus G' obtained among all oil sand tests was used to normalize the shear moduli of the three oil sand samples at the various testing conditions $\left(\mathrm{G}^{\prime}=298.0\right.$ MPa; SE-09 at $10 \mathrm{~Hz}, 20^{\circ} \mathrm{C}$ ).

Based on the observed similar trends shown in Figure 9, the combined data were used to perform regression analyses for the three oil sand samples. The normalized shear modulus $\left(G / G^{\prime}\right)$ curve with $G^{\prime}=$ 298.0 MPa for the combined test data is shown in Figure 10, and Eq 3 presents a generalized shear modulus reduction empirical model obtained from the regression analyses for the oil sand materials tested. 

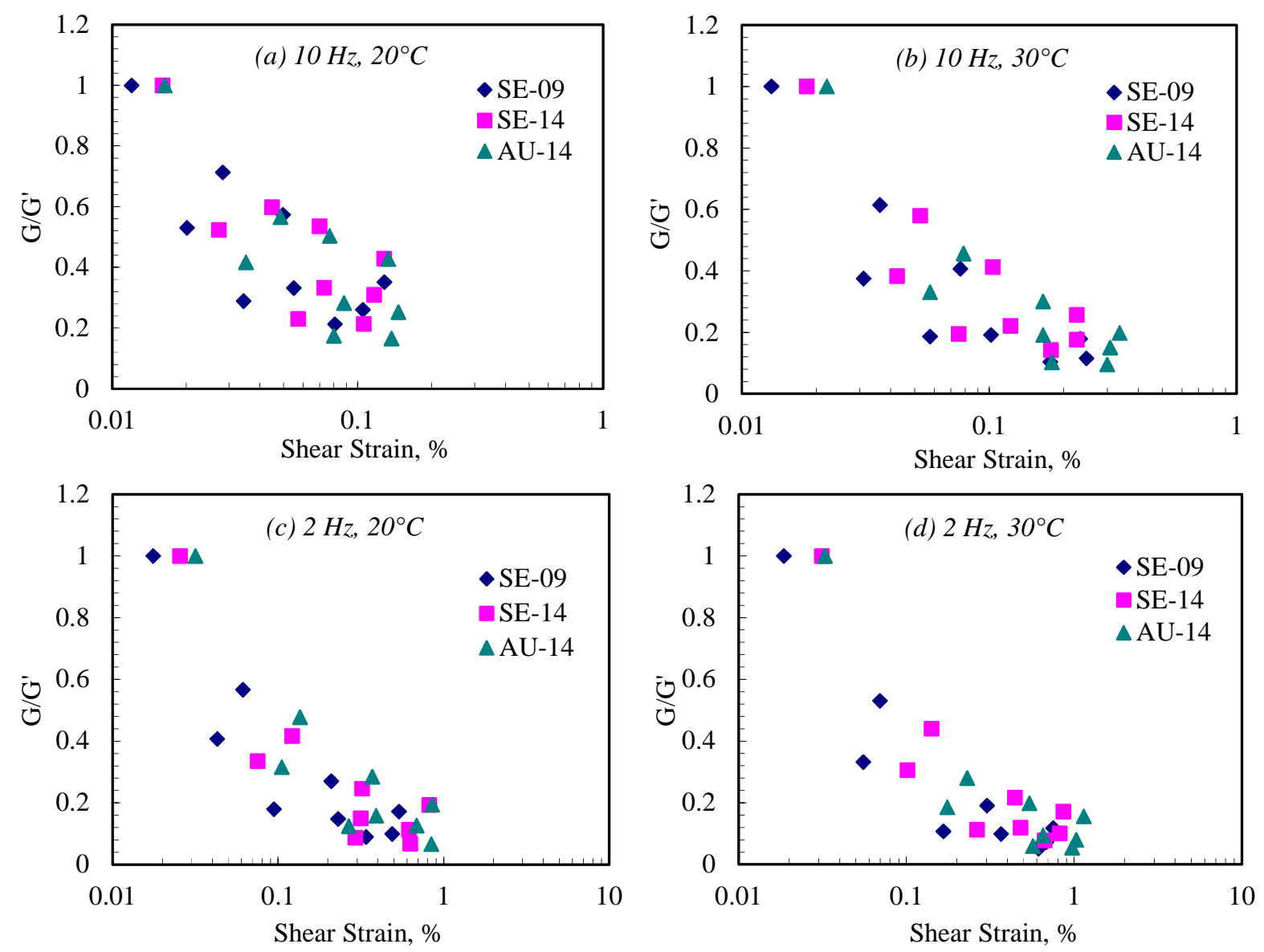

Figure 9-Normalized Shear Moduli vs. Shear Strains at Different Testing Conditions.

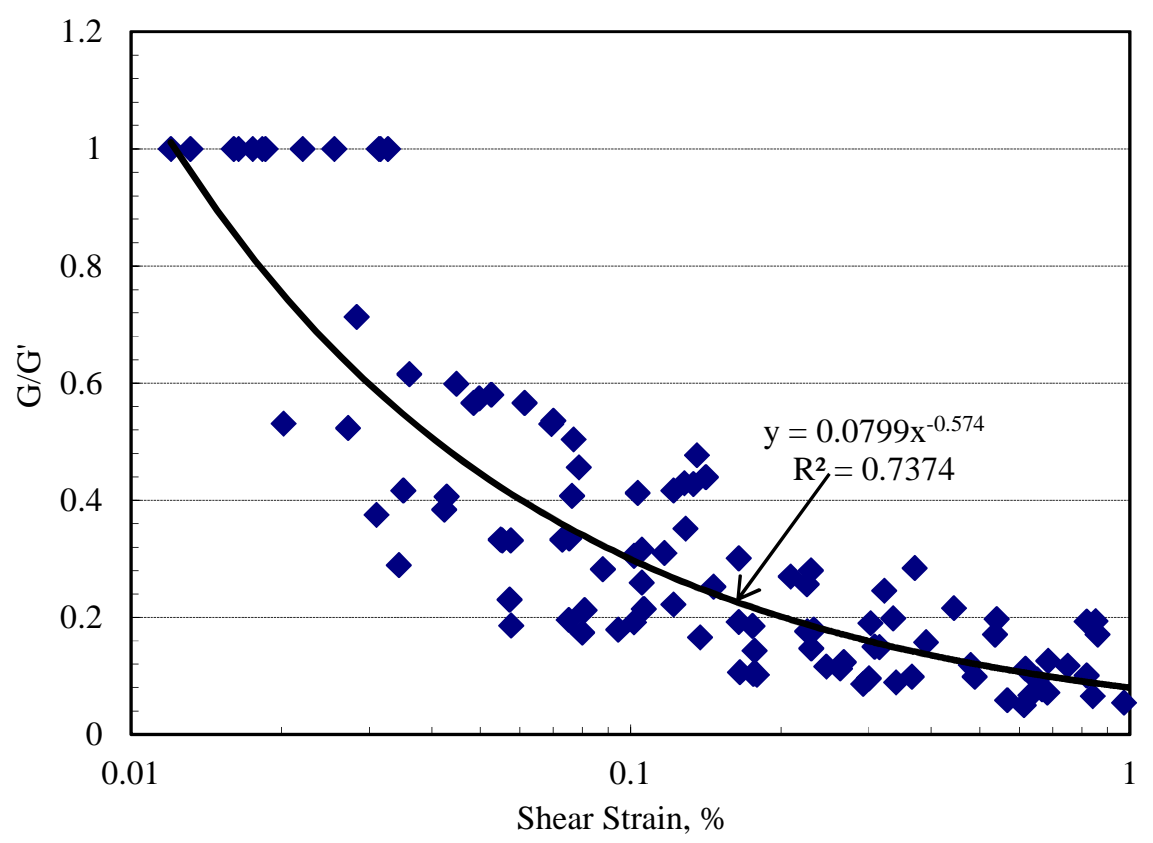

Figure 10—Normalized Shear Modulus vs. Shear Strain for Combined Oil Sands Data. 
$\frac{G}{G^{\prime}}=0.0799 \gamma^{-0.574} ; \quad \mathrm{R}^{2}=0.74$

\section{Development of Shear Modulus Characterization Models}

\section{Selection of Model Parameters}

Field studies indicated that during the hottest months in spring and summer, oil sands soften to the extent that routine operations of equipment such as trucks and shovels become problematic $[3,13]$. This behavior is widely attributed to the presence of highly viscous bitumen in the oil sand, which is affected by temperature. Therefore, a realistic oil sand characterization model should consider the effects of the loading conditions and responses as well as the physical properties (bitumen content that primarily affect stiffness behavior in the field).

In this study, the modulus data obtained from the new cyclic triaxial shear test procedure were used to develop shear modulus models for the oil sand materials tested. All the stress-strain test data obtained from the nine stress states (see Table 2) were used towards an objective to establish a basic understanding as well as to develop practical predictive equations to estimate shear stiffness behavior of oil sand materials in the field. A close examination of the test results at the different test conditions, and the physical properties of the three oil sands, such as particle size distribution, density, and water content with the assumption of similar bitumen rheological properties, suggested that the individual databases could also be combined to model the behavior of the materials. The combined database allowed bitumen content to be included as a variable in the analyses.

The correlation coefficient (R-squared) selection method in the SAS statistical software was first used to determine which independent variables were potential candidates for the oil sand models [18]. The variables used in the selection include the applied stress states and measured strains as well as the oil sand physical properties (bitumen content, water content, and gradation properties; $C_{\mathrm{u}}, C_{\mathrm{c}}$ and $D_{50}$ ). It was found that shear modulus strongly depended on the bulk stress, the octahedral shear stress, bitumen content, and temperature. Accordingly, four models were selected to study the oil sand shear stiffness 
trends. Among many mathematical forms including linear, nonlinear, and hyperbolic, the power function was the most suitable with the high correlation coefficients for modeling the oil sand shear moduli.

\section{Combined Shear Modulus Model}

Table 6 lists the generalized shear modulus models developed using the combined test data and gives the model parameters obtained from the SAS stepwise multiple regression analyses. The combined test data were analyzed to develop models of shear modulus as dependent variable and bulk stress $(\theta)$, octahedral shear stress $\left(\tau_{\text {oct }}\right)$, the bitumen content $\left(w_{\mathrm{b}}\right)$, and temperature $(T)$ as independent variables. The differences in $\mathrm{R}^{2}$ values indicate that the octahedral shear stress has a significant effect on the shear modulus. For instance, the $\mathrm{R}^{2}$ value was improved by more than $200 \%$ when the octahedral shear stress term was included in model 2, compared to less than $15 \%$ increase when bitumen content and temperature were included in the models (see models 3 and 4). This observation also suggests that specimens experienced higher dynamic loading in all directions under the new cyclic triaxial shear test loading conditions which applied dynamic radial stresses on the samples. Confining stress and shear strength properties have commonly been used to model the stiffness behavior of oil sand materials. However, a comprehensive but yet practical model should account for the effects of temperature and bitumen content in the oil sand. High $\mathrm{R}^{2}$ values obtained for models 3 and 4 indicate that temperature and bitumen content could influence the prediction of shear modulus of oil sand materials in the field. Recall that temperature and bitumen content are important factors to influence field behavior of oil sand materials [3]. Therefore, model 4 can be proposed for routine use in the estimation of shear modulus behavior of the oil sand materials in the field. Note that further validation and verification of model 4 will no doubt be needed using results of additional laboratory and field tests.

Accordingly, model 4, also presented in $\mathrm{Eq} \mathrm{4,} \mathrm{is} \mathrm{proposed} \mathrm{for} \mathrm{practical} \mathrm{use} \mathrm{for} \mathrm{shear} \mathrm{modulus}$ characterization of oil sand materials. 
Table 6-Shear modulus models developed for the oil sand materials.

\begin{tabular}{|c|c|c|c|c|c|c|c|}
\hline Model 1 & & \multicolumn{6}{|c|}{$G=A \times \theta^{k_{1}}$} \\
\hline Model 2 & & \multicolumn{6}{|c|}{$G=A \times \theta^{k_{1}} \tau_{\text {oct }}^{k_{2}}$} \\
\hline Model 3 & & \multicolumn{6}{|c|}{$G=A \times \theta^{k_{1}} \tau_{o c t}^{k_{2}} w_{b}^{k_{3}}$} \\
\hline Model 4 & & \multicolumn{6}{|c|}{$G=A \times \theta^{k_{1}} \tau_{o c t}^{k_{2}} w_{b}^{k_{3}} T^{k_{4}}$} \\
\hline \multicolumn{8}{|c|}{ Model Parameters } \\
\hline Model & $A$ & $k_{1}$ & $k_{2}$ & $k_{3}$ & $k_{4}$ & $R^{2}$ & $R M S E$ \\
\hline 1 & 0.32 & 0.866 & & & & 0.190 & 0.356 \\
\hline 2 & 0.10 & 2.019 & -1.592 & & & 0.719 & 0.211 \\
\hline 3 & 1.29 & 2.021 & -1.596 & -1.059 & & 0.795 & 0.181 \\
\hline 4 & 57.81 & 2.029 & -1.614 & -1.059 & -1.183 & 0.865 & 0.147 \\
\hline
\end{tabular}

$G=57.8 \times \theta^{2.029} \tau^{-1.614} w_{\mathrm{b}}^{-1.059} T^{-1.183} ; \quad \mathrm{R}^{2}=0.87, \quad \mathrm{RMSE}=0.147$

where:

$G \quad=$ shear modulus in $\mathrm{MPa}$,

$\theta \quad=$ bulk stress $=\sigma_{1}+\sigma_{2}+\sigma_{3} ;$ in $\mathrm{kPa}$,

$\sigma_{1} \quad=$ major principal stress in $\mathrm{kPa}$,

$\sigma_{3}=$ minor principal stress $\left(=\sigma_{2}\right.$ for triaxial test conditions $)$ in $\mathrm{kPa}$,

$\tau_{\text {oct }}=$ octahedral shear stress in $\mathrm{kPa}$,

$=\frac{1}{3} \sqrt{\left(\sigma_{1}-\sigma_{2}\right)^{2}+\left(\sigma_{1}-\sigma_{3}\right)^{2}+\left(\sigma_{2}-\sigma_{3}\right)^{2}}$

$=\frac{\sqrt{2}}{3}\left(\sigma_{1}-\sigma_{3}\right)$ for triaxial test conditions,

$w_{\mathrm{b}} \quad=$ bitumen content $(\%)$, and

$T \quad=$ temperature (degree Celsius). 
In $\mathrm{Eq} 4$, the coefficient representing model parameter $A$ is proportional to the shear modulus. The value of $A$ should be positive since shear modulus can never be negative. Also, increasing bulk stress should produce stiffening of the material, which results in higher shear modulus. That is, parameter $k_{1}$ of the bulk modulus term should also be positive. However, parameter $k_{2}$, which is the exponent of the octahedral shear stress, should be negative since increasing the shear stress decreases the shear modulus values or produced softening of the materials such as reported in test results in Table 3 and Table 4. Parameter $k_{3}$ should also be negative since shear modulus values were reduced going from the low grade SE-09 oil sand sample with $8.5 \%$ bitumen content to the high grades SE-14 and AU-14 samples with bitumen contents of $13.3 \%$ and $14.5 \%$, respectively. Similarly, $k_{4}$ should be negative since increasing the temperature decreased the shear modulus values of the oil sand materials tested. Thus, parameters $k_{3}$ and $k_{4}$ are somewhat dependent on bitumen content of the oil sand material, and the test temperature, respectively.

\section{Conclusions}

This paper presented findings from a comprehensive laboratory research study conducted at the University of Illinois on three oil sand materials with bitumen contents of $8.5 \%, 13.3 \%$ and $14.5 \%$ by weight. A new cyclic triaxial test procedure was introduced to determine shear modulus properties in the laboratory in order to closely model the behavior of oil sand materials under dynamic loading of heavy off-road haul trucks and shovels during mining operations. The following findings and conclusions are drawn from the study:

1. The proposed cyclic shear test yielded lower shear modulus values for all the oil sand samples when compared with the standard shear test. A combination of varying magnitudes of static and dynamic confining stresses applied in the proposed shear test compared to constant confining stresses applied in the standard test is suggested as the cause of the difference in the shear moduli values. 
2. The applied stress states and loading conditions have significant influence on shear modulus of the oil sand materials. Shear modulus of all three materials decreased with increasing applied cyclic stress at the two test temperatures and loading frequencies. This is an indication that oil sand materials exhibit stress dependent behavior.

3. A comprehensive shear modulus model was also developed from the test data to predict shear modulus as a function of applied confining and shear stresses, specimen bitumen content and temperature. High coefficient of correlation value obtained from the shear modulus model is an indication that the model can be used with confidence to characterize oil sand materials in the field although the model will need to be further checked using results of additional laboratory and field tests on oil sand materials for validating its accuracy and shear modulus prediction ability.

\section{Acknowledgements}

The authors would like to acknowledge Dr. Liqun Chi of Caterpillar, Inc. of Peoria, Illinois for his collaborative efforts in funding this research. Also, the immense contribution of Professor Emeritus Samuel H Carpenter of the University of Illinois at Urbana-Champaign to this study is acknowledged. 


\section{References}

[1] ASTM Standard D3999-91, 2003, "Standard Test Methods for the Determination of the Modulus and Damping Properties of Soils Using the Cyclic Triaxial Apparatus," Annual Book of ASTM Standards, Vol. 04.08, West Conshohocken, PA, 15 p.

[2] O’Reilly, M.P. and Brown, S.F. Cyclic Loading of Soils, Blackie, London, 1991, pp. 70-121.

[3] Joseph, T.G., "Physical, Static and Inferred Dynamic Loaded Properties of Oil Sand," Final Progress Report, Phases I, II, and III, Submitted to Caterpillar, Inc., 2005.

[4] Agar, J.G., Morgenstern, N.R., and J.D., Scott. "Shear Strength and Stress-Strain Behavior of Athabasca Oil Sand at Elevated Temperatures and Pressures," Can. Geotech. J., Vol. 24, 1987, pp. 1-10.

[5] Samieh, A.M. and Wong, R.C.K., "Deformation of Athabasca Oil Sand in Triaxial Compression Tests at Low Effective Stresses under Varying Boundary Conditions," Can. Geotech. J., Vol.34, 1997, pp. 985990.

[6] Samieh, A.M. and Wong, R.C.K., "Modeling the Responses of Athabasca Oil Sand in Triaxial Compression Tests at Low Pressure," Can. Geotech. J., Vol. 35, 1998, pp. 395-406.

[7] AASHTO Standard T265, 2009, "Laboratory Determination of Moisture Content of Soils," Standard Specifications for Transportation Materials and Methods of Sampling and Testing, Washington, D.C. 
[8] AASHTO Standard T308, 2009, "Standard Method of Test for Determining the Asphalt Binder Content of Hot Mix Asphalt (HMA) by the Ignition Method," Standard Specifications for Transportation Materials and Methods of Sampling and Testing, Washington, D.C.

[9] AASHTO Standard T27, 2005, "Standard Method of Test for Sieve Analysis of Fine and Coarse Aggregates," Standard Specifications for Transportation Materials and Methods of Sampling and Testing, Washington, D.C.

[10] Cameron R. and Lord E.R.F., "Compaction Characteristics of Athabasca Tar Sand and its Suitability as A Backfill Material.," Proceedings of the 4th International Conference on Heavy Crude and Tar Sands, Edmonton, Alberta, 1998.

[11] Seyhan, U., 2002, "Characterization of Anisotropic Granular Layer Behavior in Flexible Pavements, $\mathrm{PhD}$ Dissertation, Univ. of Illinois at Urbana-Champaign, Urbana, IL.

[12] AASHTO Standard T 312, 2012, "Standard Method of Test for Preparing and Determining the Density of Hot-Mix Asphalt (HMA) Specimens by Means of the Superpave Gyratory Compactor," Standard Specifications for Transportation Materials and Methods of Sampling and Testing, Washington, D.C.

[13] Joseph, T.G., “OsEIP: The Oil Sands-equipment Interactions Program,” CIM Bull., Vol. 95 (1064), 2002, pp. 58-61.

[14] Anochie-Boateng J, Tutumluer E. "Shear Strength Properties of Naturally Occurring Bituminous Sands," Proceedings of the 8th International Annual Bearing Capacity of Roads, Railways and Airfields Conference, Champaign, IL, June 29-July 2, 2009, 2009. 
[15] Hardin, B.O., and Drnevich, V.P. "Shear Modulus and Damping in Soils: Design Equation and Curves,"J Soil Mech Found Div. ASCE, Vol. 98 (SM7), 1972, pp. 667-691.

[16] Seed H.B, and Idriss I.M., "Soil Moduli and Damping Factors for Dynamic Response Analyses," Report EERC 70-10, Earthquake Engineering Research Center, Univ. of California, Berkeley, CA, 1970

[17] Kramer S.L. Geotechnical Earthquake Engineering, Prentice-Hall Inc, Upper Saddle River, NJ, 1996.

[18] Delwiche, L.D. and Slaughter, S.J., The little SAS Book, SAS Institute, Cary, NC, 2008. 